Document downloaded from:

http://hdl.handle.net/10251/121791

This paper must be cited as:

Carpitella, S.; Certa, A.; Izquierdo Sebastián, J.; La Fata, CM. (2018). A combined multicriteria approach to support FMECA analyses: a real-world case. Reliability Engineering \& System Safety. 169:394-402. https://doi.org/10.1016/j.ress.2017.09.017

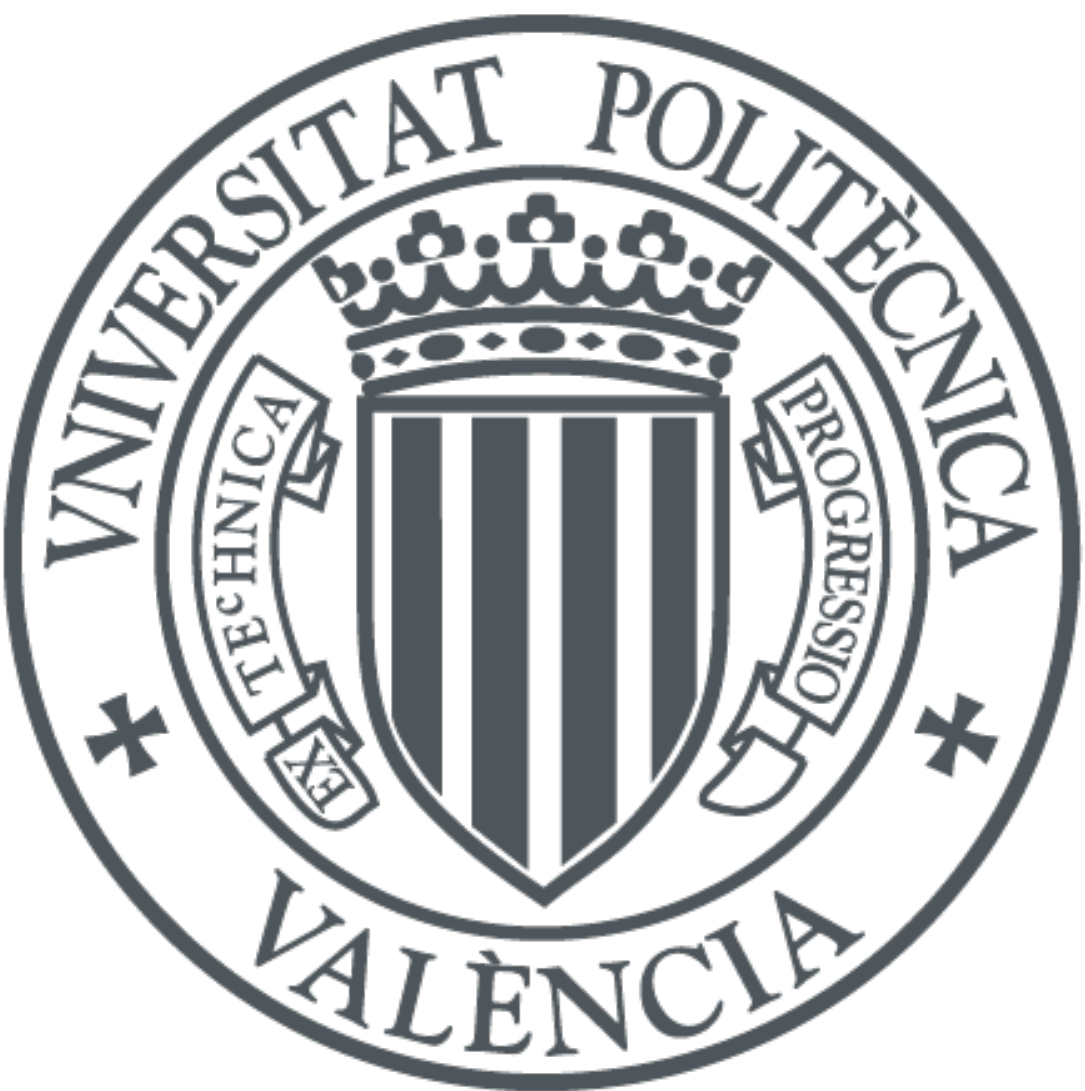

The final publication is available at

http://doi.org/10.1016/j.ress.2017.09.017

Copyright Elsevier

Additional Information 


\title{
A combined multi-criteria approach to support FMECA analyses: a real-world case
}

Silvia Carpitella ${ }^{1}$, Antonella Certa ${ }^{2}$, Joaquín Izquierdo ${ }^{3}$, Concetta Manuela La Fata ${ }^{4}$

1,2,4 Dipartimento dell'Innovazione Industriale e Digitale (DIID)-Università degli Studi di Palermo,

Palermo, Italy, silvia.carpitella@unipa.it, antonella.certa@unipa.it,

concettamanuela.lafata@unipa.it

${ }^{3}$ Instituto de Matemática Multidisciplinar/Universitat Politècnica de València, Valencia, Spain, jizquier@upv.es

\begin{abstract}
The paper proposes an approach that combines reliability analyses and multi-criteria decision methods to optimize maintenance activities of complex systems. A failure mode, effects, and criticality analysis (FMECA) is initially performed and the fuzzy TOPSIS (FTOPSIS) method is then applied to rank previously identified failure modes. For prioritization, failure modes are assessed against three evaluation criteria that differ from those traditionally involved in risk priority number (RPN) computation (i.e. severity, occurrence and detection). Two criteria refer to the maintenance management reflecting the operational time taken by the maintenance activity performed after the occurrence of a specific fault, and the way such an action is executed. The third criterion reflects the classical frequency of the occurrence of faults. To further develop previous research, the analytic hierarchy process (AHP) is herein applied to weight evaluation criteria and a group of experts is involved with aspects associated with the considered criteria. The approach is applied to a real-world case study, showing that the obtained results represent a significant driver in planning maintenance activities. To test the influence of criteria weights on ranking results, a sensitivity analysis is carried out by varying the vector of criteria weights obtained from the group decision process.
\end{abstract}

Keywords: safety-critical analysis, FMECA, FTOPSIS, AHP

\section{Introduction and literature review}

Maintenance is recognized as one of the main asset management subject areas [1] needing to be effectively accomplished and controlled to improve the performance of complex systems (i.e. availability, reliability, production level, costs, safety, etc.) in various operational environments [27]. Obviously, maintenance activities must be integrated and scheduled within the life cycle of the system under investigation and need to take into consideration the reliability features required by the system itself. Panteleev et al. [8] emphasize the role of the maintenance and repair organization (MRO) and highlight the importance of implementing and planning periodic maintenance actions 
on machines to positively impact their life cycle. The importance of maintenance scheduling is also emphasized by Certa et al. [9] who deal with the problem of selecting the elements of a repairable and stochastically deteriorating multi-component system to be replaced during each scheduled and periodic system stop within a finite optimization cycle. The simultaneous minimization of total expected maintenance cost and system unavailability is ensured by means of a mathematical programming-based approach. In [10], the authors formulate a constrained mathematical model to determine both the optimal number of periodic inspections within a finite time frame and the system elements to be replaced during each scheduled inspection. A further mathematical model is proposed by Taghipour et al. [11] to identify the optimal periodicity of the inspection intervals for a repairable system subjected to hidden failures over finite and infinite optimization times. The objective function to be optimized is the total expected cost. Yang et al. [12] underline the importance of optimizing the scheduling of inspection, repair, and replacement activities in preventive maintenance policies. The authors propose a replacement policy to maximize reliability in a mission-based system.

One of the main reliability analysis methods used to determine maintenance action priority is failure modes and effect analysis (FMEA). As established by the CEI EN 60812 standard [13], the extension of FMEA is referred to as failure modes, effects, and criticality analysis (FMECA) and represents a valid support method to semi-quantitatively measure the criticality of system failure modes. Many authors [14, 15] consider FMECA and the development of risk analyses as an essential part of maintenance management strategies. Vernez and Vuille [16] emphasize the good adaptability of FMECA as a tool for analyzing complex macro-systems with various hierarchical levels. They support the use of the methodology for the reliability optimization and the identification of major system vulnerabilities.

Criticality analyses of failure modes are typically based on the three risk parameters of severity (S), occurrence $(\mathrm{O})$ and detection (D) whose product returns the risk priority number (RPN). Despite its wide use, the classical RPN has been widely criticized for having many shortcomings. As a result, numerous enhanced versions of the traditional FMECA have been proposed in the literature. Carmignani [17] suggests the use of a fourth parameter in the RPN calculation. The author proposes taking into account profitability - based on costs and possible profits after minimizing losses due to failures. Bevilacqua, Braglia, and Gabbrielli [18] propose a modified FMECA where the RPN consists of the weighted sum of six parameters (safety, importance of the machine for the process, maintenance costs, failure frequency, downtime length, and operating conditions). Furthermore, a sensitivity analysis based on the Monte Carlo simulation to verify the robustness of the final results is performed. Yang et al. [19] underline how, especially when multiple experts give differing 
evaluations about the same failure mode, the use of the evidence theory [20-22] represents a valid support to manage the uncertainty that characterizes this type of evaluation.

Most works in the literature propose the support of multi-criteria decision methods (MCDM) to carry out FMEA and FMECA analyses. Liu et al. [23] review 75 papers on FMEA to emphasize its strengths and weaknesses in many practical applications. Braglia [24] proposes the analytic hierarchy process (AHP) [25] to pairwise compare the potential causes of failure by assuming as criteria the classical risk factors $\mathrm{S}, \mathrm{O}$, and $\mathrm{D}$ together with the expected cost due to failures. Braglia and Bevilacqua [26] also suggest the use of the AHP to support the maintenance staff in the identification of failure mode criticality. In Zammori and Gabbrielli [27], the FMEA is combined with the analytic network process (ANP) technique [28] to take into account possible interactions among the principal causes of failure. Emovon et al. [29] prioritize the analyzed risk factors with the aim of making a detailed and realistic study of marine machinery systems by means of the VIKOR method [30]. Braglia, Frosolini and Montanari [31] develop a fuzzy criticality assessment model that is easy to implement and design. They present a risk function where 'if-then' fuzzy rules are automatically generated and the proposed methodology is tested in a real process plant. To take into account the uncertainty that often occurs in the evaluation of parameters $\mathrm{O}, \mathrm{S}$, and $\mathrm{D}$, the authors propose the fuzzy-technique for order preference by similarity to ideal solution (FTOPSIS) [32-35]. A combined FTOPSIS and fuzzy-AHP [36] approach to FMECA is proposed by Kutlu and Ekmekçioğlu [37]. The fuzzy-AHP method is applied to weight the risk factors that are successively used within the FTOPSIS approach to obtain the final closeness coefficients on the basis of which failure modes are prioritized. Alternatively to the traditional RPN method, the ELECTRE TRI technique [38] is proposed in [39] to directly assign failure modes into predefined and ordered risk classes. In [40], crisp or interval-valued opinions on $\mathrm{O}, \mathrm{S}$ and D are elicited from a team of equally credible and reliable experts, and a multiple-value characterization of RPNs is obtained by means of a novel evidence theory-based FMECA methodology.

The theoretical contribution of the present research is a multi-criteria multi-decision making approach to support analysts in the risk evaluation field; and with the final aim of identifying, during the planning phase, the necessary maintenance actions. An FMECA analysis is initially performed to examine the criticality of failure modes in a real-world case study. The proposed approach assesses identified failure modes against three evaluation criteria - which differ from those traditionally involved in the RPN computation (i.e. severity, occurrence, and detection). In a first step, a team of experts helped identify and evaluate the relative priority of each criterion. That is, the criteria are identified within the analyzed engineering scenario, namely the development of a new and innovative street-cleaning vehicle endowed with a smart remote diagnosis - telediagnosis - system that features a multi-decision-making process. The first two criteria refer to the 
management of maintenance activities and reflect the operational time taken by a maintenance activity after the occurrence of a specific fault, and how such an action is executed. The third criterion reflects the frequency of faults. For the aim of the previously mentioned first step, a process is proposed that translates the technical skills acquired by the experts to maintenance management. It consists in a multi-criteria decision-making process via AHP that derives the weights of the criteria by taking into account the decision-making ability and experience of each expert. Furthermore, to obtain reliable data that incorporates uncertainty as confirmed by the experts, a mechanism that can lead and support the experts in a simple process of elicitation of judgments is proposed. Specifically, to express the judgments related to each failure mode, linguistic terms (successively translated into fuzzy numbers) for each evaluation criterion are put to the experts. This phase of the proposed analysis is supported by the FTOPSIS approach. The proposed approach differs from the others quoted at the end of the previous paragraph in relation to the necessity and future interest of the real-world case study. In the authors' opinion only the research proposed by Kutlu and Ekmekçioğlu [37] shows a similar approach. However, the study by Kutlu and Ekmekçioğlu is based on fuzzy AHP; while a consensual AHP process using a group decision approach is herein suggested. This consensus is used to derive the priorities of the evaluation criteria, thus embodying the priorities obtained from the decision-making abilities of all the experts, a characteristic not considered by Kutlu and Ekmekçioğlu.

The present research is a substantial extension of the previous work [41] that proposes a decision support tool, based on FTOPSIS and AHP, to perform a reliability analysis with relation to a subsystem (of the system herein analyzed), in which the process of eliciting judgments from experts did not contemplate a consensus obtained from a modelling of the differing decision-making power of each expert.

The remainder of the paper is organized as follows. In Section 2, the FMECA technique is described. After briefly summarizing AHP, the proposed FTOPSIS-based approach to prioritize failure modes is presented in Section 3. Section 4 describes the application to a real-world application case related to a street cleaning vehicle. Finally, the conclusions section closes the work.

\section{Failure modes, effects, and criticality analysis (FMECA)}

On the basis of the CEI EN 60812 standard [13], FMEA is a systematic procedure for the analysis of a system to identify potential failure modes, and their causes and effects on system performance. FMECA is an extension of FMEA that enables prioritizing failure modes on the basis of their criticality. Specifically, the criticality of each failure mode is computed by combining the risk parameters $\mathrm{S}, \mathrm{O}$ and $\mathrm{D} . \mathrm{S}$ is an estimate of how strongly the failure mode will affect the system, $\mathrm{O}$ is the frequency of occurrence of the failure mode within a determined period of time, and D 
represents the probability of detecting the failure. For each failure mode, the product of parameters O, S, and D leads to the RPN (Eq. 1):

$$
\mathrm{RPN}=\mathrm{S} \cdot \mathrm{O} \cdot \mathrm{D}
$$

Each risk factor generally takes a discrete value in the range $[0,10]$.

The first step in FMECA is the description of the considered system and the construction of a hierarchical structure. To obtain an exhaustive description of the system, it is firstly necessary to gather information about the reliability relations among the system components and physically describe them with their own order and position (defining system boundaries and levels). It is clearly suggested that those components that will be not be evaluated nor taken into consideration in the analysis are excluded from the study. The functional relationships among components can be finally formalized in a system block diagram. Moreover, it is necessary to define all the possible failure modes for each component, detect the failure causes, and define both the local and the system level failure effects. All the results must be summarized in worksheets that support the analyst in formalizing the phase of risk evaluation, namely the computation of the RPN related to each failure mode.

\section{Multi-criteria decision methods (MCDMs) to support FMECA}

The present research proposes a structured method that combines AHP and FTOPSIS with the aim of supporting a group of decision makers performing FMECA to prioritize failure modes. Since multiple decision makers and evaluation criteria are considered in the analysis, the AHP method is specifically proposed to weight criteria by considering the preferences of the decision-making group. So far, the AHP method has been widely proposed in diverse fields of research such as transport [42], water management [43], and software selection [44]. AHP is particularly suitable to deal with group decisions arising from the involvement of many stakeholders with interests/objectives that may be conflicting, and to derive the criteria priorities considered in making decisions $[45,46]$. FTOPSIS is then proposed to carry out the criticality analysis of failure modes. A brief description of AHP and FTOPSIS is provided in the following sub-sections.

\subsection{AHP to derive evaluation criteria priorities}

The AHP [47] represents a valid tool for making decisions and is grounded upon the concept of pairwise comparison judgments. Its application enables convergence to a shared choice among various decision makers who express their preference judgments on elements (criteria, sub-criteria, and alternatives) under comparison. In the present paper, AHP is used to derive the relative priorities of evaluation criteria that are successively considered in the FTOPSIS approach for the ranking of failure modes. 
The AHP decomposes the decision problem into sets of elements, according to several common characteristics and levels. The topmost level is the "focus" of the problem or ultimate goal, the intermediate levels correspond to criteria and sub-criteria, while the lowest level contains the "decision alternatives". If each element of each level depends on all elements of the upper level, then the hierarchy is complete, otherwise, it is considered incomplete. Elements of each level are pairwise compared with respect to a specific element of the immediate upper level by means of grades and numerical values from the Saaty scale [48] (Table 1), and then collected into the socalled pairwise comparison matrix. An AHP group decision making process $[49,50]$ is herein proposed to weight criteria. Each decision maker is asked to express a pairwise comparison judgment for each couple of criteria.

TABLE I. SAATY SCALE

\begin{tabular}{|c|c|}
\hline Numerical values & Verbal pairwise comparisons \\
\hline 1 & Equal importance of two elements \\
3 & Moderate importance of one element over another \\
5 & Strong importance of one element over another \\
7 & Very strong importance of one element over another \\
9 & Extreme importance of one element over another \\
$2,4,6,8$ & Intermediate values \\
\hline
\end{tabular}

The method suggests aggregating these judgments into a matrix (i.e. group aggregated matrix) by means of the geometrical mean [45] that assures the reciprocity of pairwise judgments.

To maintain a reasonable consistency of pairwise comparisons, Saaty [51] argued that the number of considered factors must be less than or equal to nine. In addition, AHP allows inconsistency and provides a measure of such an inconsistency for each set of judgments. Specifically, the consistency of the judgmental matrix can be determined by a measure called the consistency ratio $(C R)$ defined as follows (Eq. 2):

$$
C R=\frac{C I}{R I},
$$

where $C I$ is the consistency index and $R I$ is the random index.

For a matrix of order $n, C I$ is defined as:

$$
C I=\frac{\lambda_{\max }-n}{n-1}
$$

in which $\lambda_{\max }$ is the largest eigenvalue of the pairwise comparisons matrix.

About RI, Saaty [47] defines the RI value as the average value of CIs related to randomly generated matrices of order $n$ (Table II). 
TABLE II. RANDOM INDEX VALUES

\begin{tabular}{|c|c|c|c|c|c|c|c|c|c|c|}
\hline $\boldsymbol{n}$ & 1 & 2 & 3 & 4 & 5 & 6 & 7 & 8 & 9 & 10 \\
\hline $\boldsymbol{R I}$ & 0 & 0 & 0.52 & 0.89 & 1.11 & 1.25 & 1.35 & 1.4 & 1.45 & 1.49 \\
\hline
\end{tabular}

Generally speaking, a $C R$ value of 0.1 or less implies an acceptable inconsistency. Such a threshold is 0.08 for matrices of size four and 0.05 for matrices of size three. If the $C R$ value is greater, the judgments may not be reliable and should be elicited again. This methodology may be complemented with techniques for consistency improvement [52-54], including the necessary feedback with expert(s) [55], and with the treatment of incomplete judgments that may characterize comparison matrices [56] - a current issue discussed in the literature.

\subsection{FTOPSIS-based approach to prioritize failure modes}

The traditional TOPSIS was originally developed by Hwang and Yoon [33] as an MCDM for ranking alternatives on the basis of their crisp ratings on different qualitative and/or qualitative criteria, the latter being opportunely weighted. It is grounded on the concept of distances between each alternative and the positive and the negative ideal solutions. Therefore, the best alternative among those evaluated is that characterized by the shortest distance from the positive ideal solution and the greatest distance from the negative ideal. Given its ability to deal with different decision problems regarding the ranking of alternatives, the literature offers numerous contributions about the application of TOPSIS in diverse fields $[57,58]$ even characterized by uncertain and imprecise input data [59]. The TOPSIS method may involve a single analyst (i.e. decision maker) or a group of decision makers [60,61].

Nevertheless, in practical real-life situations, human judgments are often vague and uncertain so that eliciting exact numerical values is difficult. More realistically, experts are better able to express their judgments on criteria weights and/or alternative ratings by means of linguistic variables. With this recognition, the traditional TOPSIS was extended by Chen [32] under a fuzzy environment where linguistic variables are used to rate alternatives and/or weight criteria. Such a fuzzy extension of TOPSIS is referred to as FTOPSIS. The FTOPSIS is applied in the present paper to the failure modes prioritization aim.

The first step of FTOPSIS is the definition of the fuzzy decision matrix $\tilde{\boldsymbol{X}}$ (4):

$$
\tilde{\boldsymbol{X}}=\left[\begin{array}{lll}
\tilde{x}_{11} & \ldots & \tilde{x}_{1 n} \\
\ldots & \ldots & \ldots \\
\tilde{x}_{m 1} & \ldots & \tilde{x}_{m n}
\end{array}\right],
$$

where the generic component $\tilde{x}_{i j}$ is the fuzzy number that represents the rating of the alternative $i$ under the criterion $j$. Fuzzy numbers used here are either triangular (TFN) or trapezoidal (TrFN) 
fuzzy numbers [62], fully characterized by the following triple (Eq. 5) and quadruple (Eq. 6) sets of ordered numbers, respectively:

$$
\begin{gathered}
\tilde{x}_{i j}=\left(a_{i j}, b_{i j}, c_{i j}\right), \\
\tilde{x}_{i j}=\left(a_{i j}, b_{i j}, c_{i j}, d_{i j}\right) .
\end{gathered}
$$

Matrix $\tilde{\boldsymbol{X}}$ must be normalized with relation to each criterion to obtain the normalized decision matrix $\tilde{Z}(7)$ :

$$
\tilde{\boldsymbol{Z}}=\left[\begin{array}{lll}
\tilde{Z}_{11} & \ldots & \widetilde{z}_{1 n} \\
\ldots & \ldots & \ldots \\
\tilde{Z}_{m 1} & \ldots & \tilde{Z}_{m n}
\end{array}\right],
$$

where elements, considering TFNs, are obtained as follows (Eqs. 8 and 9):

$$
\begin{gathered}
\tilde{z}_{i j}=\left(\frac{a_{i j}}{c_{j}^{*}}, \frac{b_{i j}}{c_{j}^{*}}, \frac{c_{i j}}{c_{j}^{*}}\right), j \in I^{\prime}, \\
\widetilde{z}_{i j}=\left(\frac{a_{j}^{-}}{c_{i j}}, \frac{a_{j}^{-}}{b_{i j}}, \frac{a_{j}^{-}}{a_{i j}}\right), j \in I^{\prime \prime} .
\end{gathered}
$$

In (8) and (9), $I^{\prime}$ is the subset of criteria to be maximized, $I^{\prime \prime}$ is the subset of criteria to be minimized, whereas $c_{j}^{*}$ and $a_{j}^{-}$are computed as follows (Eqs. 10 and 11):

$$
\begin{gathered}
c_{j}^{*}=\max _{i} c_{i j} \text { if } j \in I^{\prime}, \\
a_{j}^{-}=\min _{i} a_{i j} \text { if } j \in I^{\prime \prime} .
\end{gathered}
$$

Analogously, considering TrFNs, the elements of matrix $\tilde{Z}$ (7) are obtained as follows (Eqs. 12 and $13)$ :

$$
\begin{aligned}
& \tilde{z}_{i j}=\left(\frac{a_{i j}}{d_{j}^{*}}, \frac{b_{i j}}{d_{j}^{*}}, \frac{c_{i j}}{d_{j}^{*}}, \frac{d_{i j}}{d_{j}^{*}}\right), j \in J^{\prime}, \\
& \tilde{z}_{i j}=\left(\frac{a_{j}^{-}}{d_{i j}}, \frac{a_{j}^{-}}{c_{i j}}, \frac{a_{j}^{-}}{b_{i j}}, \frac{a_{j}^{-}}{a_{i j}}\right), j \in J^{\prime \prime},
\end{aligned}
$$

$J^{\prime}$ being the subset of criteria to be maximized and $J^{\prime \prime}$ the subset of criteria to be minimized. $d_{j}^{*}$ and $a_{j}^{-}$are (Eqs. 14 and 15):

$$
\begin{aligned}
& d_{j}^{*}=\max _{i} d_{i j} \text { if } j \in J^{\prime}, \\
& a_{j}^{-}=\min _{i} a_{i j} \text { if } j \in J^{\prime \prime} .
\end{aligned}
$$


The weighted and normalized matrix $\tilde{\boldsymbol{U}}$ is then computed to account for the different criteria weights. Thus, the generic component $\tilde{u}_{i j}$ of the matrix $\tilde{\boldsymbol{U}}$ is calculated by the equation (16):

$$
\tilde{u}_{i j}=\tilde{z}_{i j} \cdot w_{j},
$$

$w_{j}$ being the relative importance weight of criterion $j$.

Referring to the matrix $\tilde{U}$, the fuzzy positive ideal solution $A^{*}$ (Eq. 17) and the fuzzy negative ideal solution $A^{-}$(Eq. 18) are chosen as follows:

$$
\begin{aligned}
& A^{*}=\left(\tilde{u}_{1}^{*}, \tilde{u}_{2}^{*}, \ldots, \tilde{u}_{n}^{*}\right), \\
& A^{-}=\left(\tilde{u}_{1}^{-}, \widetilde{u}_{2}^{-}, \ldots, \tilde{u}_{n}^{-}\right) .
\end{aligned}
$$

For TFNs, $\tilde{u}_{j}^{-}=(0,0,0)$ and $\tilde{u}_{j}^{*}=(1,1,1)$ with $j=1, \ldots, n$. Analogously, $\tilde{u}_{j}^{-}$and $\tilde{u}_{j}^{*}$ are $(0,0,0,0)$ and $(1,1,1,1)$ respectively when TrFNs are considered.

Distances between each alternative and $A^{*}$ and $A^{-}$are then computed by means of the vertex method [32]. Accordingly, the distance $d(\tilde{m}, \tilde{n})$ between the two TFNs $\tilde{m}=\left(m_{1}, m_{2}, m_{3}\right)$ and $\tilde{n}=\left(n_{1}, n_{2}, n_{3}\right)$ is a crisp value determined by the equation (19):

$$
d(\tilde{m}, \tilde{n})=\sqrt{\frac{1}{3} \cdot\left[\left(m_{1}-n_{1}\right)^{2}+\left(m_{2}-n_{2}\right)^{2}+\left(m_{3}-n_{3}\right)^{2}\right]} .
$$

Similarly, the distance between two generic TrFNs [63] $\tilde{t}=\left(t_{1}, t_{2}, t_{3}, t_{4}\right)$ and $\tilde{r}=\left(r_{1}, r_{2}, r_{3}, r_{4}\right)$ is the following crisp value (Eq. 20):

$$
d(\tilde{t}, \tilde{r})=\sqrt{\frac{1}{4} \cdot\left[\left(t_{1}-r_{1}\right)^{2}+\left(t_{2}-r_{2}\right)^{2}+\left(t_{3}-r_{3}\right)^{2}+\left(t_{4}-r_{4}\right)^{2}\right]} .
$$

Therefore, for each alternative $i$, aggregating with respect to the whole set of criteria, the related distances from $A^{*}$ and $A^{-}$can be respectively calculated by equations (21) and (22):

$$
\begin{aligned}
& d_{i}^{*}=\sum_{j=1}^{n} d\left(\tilde{u}_{i j}, \tilde{u}_{j}^{*}\right), i=1, \ldots, n, \\
& d_{i}^{-}=\sum_{j=1}^{n} d\left(\tilde{u}_{i j}, \tilde{u}_{j}^{-}\right), i=1, \ldots, n .
\end{aligned}
$$

To rank alternatives, the closeness coefficient $C C_{i}$ is finally computed using the equation (23):

$$
C C_{i}=\frac{d_{i}^{-}}{d_{i}^{-}+d_{i}^{*}}
$$

Thus, referring to the proposed analysis and, according to the obtained $C C_{i}$ values, the ranking order of all failure modes can be determined. 


\section{Application of the described FTOPSIS-based approach to the FMECA: a real-world case}

The FTOPSIS-based approach described in the previous section has been applied to a real street cleaning vehicle. This application was carried out using the results of a project in which the University of Palermo was involved as a partner with other enterprises. The project examined the development of a new and innovative street cleaning vehicle with a telediagnosis system.

The cleaning service activities carried out by the vehicle are related to three macro phases:

- handling of the vehicle;

- waste collection; and

- tank emptying.

The phase of handling the street cleaning vehicle takes place as follows:

- repositioning on the street (at high speed) from the starting point to the destination point;

- reduction of vehicle speed and positioning of the vehicle for waste collection (using a brush, lateral rollers, and a rear roller until contact with the street is achieved using hydraulic actuators).

As the service activities are described above, it is now possible to identify the subsystems of the street vehicle, represented in the Figure 1 block diagram:

1. power take-off;

2. oil tank;

3. moving system;

4. sweeping system;

5. loading and emptying system.

Each subsystem is, in its turn, decomposed into components, as illustrated in Figure 1, in which the street cleaning vehicle is also described. For each sub-system, an exhaustive list of failure modes has been obtained using classical FMEA. Each sub-system $(1,2, \ldots, 5)$ is characterized by a certain number of failure modes progressively tagged by A, B, .., F. For instance, the ID 5.2.1.A in Table $\mathrm{X}$ indicates the failure mode " $\mathrm{A}$ " (hydraulic engine fault) of component "5.2.1" (rear roller). 
Moving System (3.)
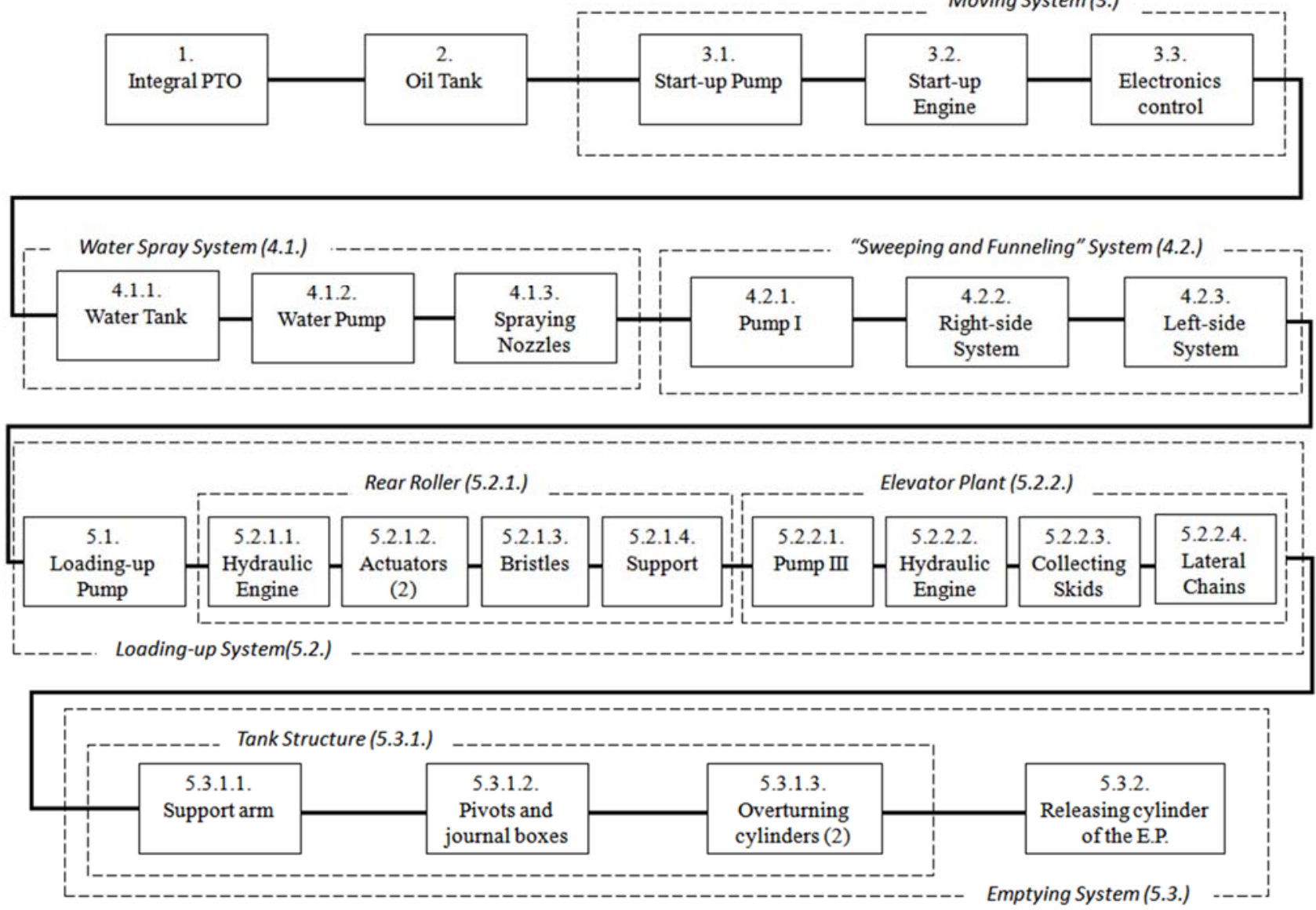

Figure 1. System block diagram

Each failure mode has been assessed against the three risk parameters (i.e. criteria) $C_{1}, C_{2}$ and $C_{3}$ reported in Table III. The first two criteria are related to the severity parameter, whereas the last criterion concerns frequency of occurrence. $\mathrm{C}_{1}$ and $\mathrm{C}_{2}$ both refer to the execution of maintenance activities related to a specific fault and respectively represent the operational time (expressed in hours), and the modality of the maintenance action execution (expressed using a quantitative scale of difficulty values). In detail, a maintenance action implies a lower level of difficulty if carried out in the same place where the failure occurred, and by an immediately available operator. Similarly, the maintenance action is medium-complex when it is necessary to ask for a specialized maintenance team. Finally, the action is complex if the repair action must be performed in a repair shop (by also considering the vehicle transport time).

TABLE III. EVALUATION CRITERIA

\begin{tabular}{|c|c|c|}
\hline Criteria & Description & $\boldsymbol{w}_{\boldsymbol{C}}$ \\
\hline $\mathrm{C}_{1}$ & Time of operation & 0.409 \\
$\mathrm{C}_{2}$ & Modality of execution & 0.197 \\
$\mathrm{C}_{3}$ & Frequency of occurrence & 0.394 \\
\hline
\end{tabular}

Weights of criteria reported in Table III arise from the application of the AHP method described in Section 3.1. A group of three differently weighted decision makers $\left(D_{1}, D_{2}, D_{3}\right)$, responsible for 
maintenance activities, were involved. Weights assigned to decision makers $\mathrm{D}_{1}, \mathrm{D}_{2}, \mathrm{D}_{3}$ are $1 / 4,1 / 2$, and $1 / 4$ respectively. Pairwise comparisons between criteria were then elicited from $\mathrm{D}_{1}, \mathrm{D}_{2}$ and $\mathrm{D}_{3}$ using the Saaty scale reported in Table I. Tables IV V, VI show the corresponding pairwise comparison matrices.

TABLE IV D PAIRWISE COMPARISONS

\begin{tabular}{|l|c|c|c|}
\hline $\mathbf{D}_{\mathbf{1}}$ & $\mathbf{C}_{\mathbf{1}}$ & $\mathbf{C}_{\mathbf{2}}$ & $\mathbf{C}_{\mathbf{3}}$ \\
\hline $\mathbf{C}_{\mathbf{1}}$ & 1 & $1 / 4$ & $1 / 7$ \\
\hline $\mathbf{C}_{\mathbf{2}}$ & 4 & 1 & $1 / 3$ \\
\hline $\mathbf{C}_{\mathbf{3}}$ & 7 & 3 & 1 \\
\hline
\end{tabular}

TABLE V. D D PAIRWISE COMPARISONS

\begin{tabular}{|l|c|c|c|}
\hline $\mathbf{D}_{\mathbf{2}}$ & $\mathbf{C}_{\mathbf{1}}$ & $\mathbf{C}_{\mathbf{2}}$ & $\mathbf{C}_{\mathbf{3}}$ \\
\hline $\mathbf{C}_{\mathbf{1}}$ & 1 & 5 & 2 \\
\hline $\mathbf{C}_{\mathbf{2}}$ & $1 / 5$ & 1 & $1 / 4$ \\
\hline $\mathbf{C}_{\mathbf{3}}$ & $1 / 2$ & 4 & 1 \\
\hline
\end{tabular}

TABLE VI. D 3 PAIRWISE COMPARISONS

\begin{tabular}{|l|c|c|c|}
\hline $\mathbf{D}_{\mathbf{3}}$ & $\mathbf{C}_{\mathbf{1}}$ & $\mathbf{C}_{\mathbf{2}}$ & $\mathbf{C}_{\mathbf{3}}$ \\
\hline $\mathbf{C}_{\mathbf{1}}$ & 1 & 2 & 3 \\
\hline $\mathbf{C}_{\mathbf{2}}$ & $1 / 2$ & 1 & 2 \\
\hline $\mathbf{C}_{\mathbf{3}}$ & $1 / 3$ & $1 / 2$ & 1 \\
\hline
\end{tabular}

Table VII reports the corresponding $C R$ values.

TABLE VII. CR VALUES

\begin{tabular}{|c|c|c|c|}
\hline \multirow{2}{*}{$C R$} & $\mathbf{D}_{\mathbf{1}}$ & $\mathbf{D}_{\mathbf{2}}$ & $\mathbf{D}_{\mathbf{3}}$ \\
\cline { 2 - 4 } & 0.03 & 0.02 & 0.00877 \\
\hline
\end{tabular}

Table VIII shows the fuzzy scales $[34,54]$ used by the three decision makers to rate failure modes against criteria (Figures 2-4).

TABLE VIII LINGUISTIC TERMS AND ASSOCIATED FUZZY NUMBERS

\begin{tabular}{|c|c|c|c|c|c|c|c|c|}
\hline \multicolumn{3}{|c|}{$\mathbf{C}_{1}$} & \multicolumn{3}{|c|}{$\mathrm{C}_{2}$} & \multicolumn{3}{|c|}{$\mathrm{C}_{3}$} \\
\hline $\begin{array}{c}\text { Linguistic } \\
\text { term }\end{array}$ & $\begin{array}{c}\text { Fuzzy } \\
\text { number }\end{array}$ & $\begin{array}{c}\text { Type } \\
\text { of } \\
\text { FN }\end{array}$ & $\begin{array}{l}\text { Linguistic } \\
\text { term }\end{array}$ & $\begin{array}{c}\text { Fuzzy } \\
\text { number }\end{array}$ & $\begin{array}{l}\text { Type of } \\
\text { FN }\end{array}$ & $\begin{array}{c}\text { Linguistic } \\
\text { term }\end{array}$ & $\begin{array}{c}\text { Fuzzy } \\
\text { number }\end{array}$ & $\begin{array}{l}\text { Type of } \\
\text { FN }\end{array}$ \\
\hline $\begin{array}{l}\text { Very Low } \\
\text { (VL) }\end{array}$ & $(0,0,1 / 2,3 / 2)$ & TrFN & $\begin{array}{l}\text { Low impact } \\
\text { (LI) }\end{array}$ & $(1,2,3)$ & TFN & $\begin{array}{l}\text { Improbable } \\
\text { (I) }\end{array}$ & $(0,0,1,3)$ & TrFN \\
\hline $\begin{array}{c}\text { Low } \\
\text { (L) }\end{array}$ & $(1 / 2,3 / 2,5 / 2)$ & TFN & & & & $\begin{array}{l}\text { Remote } \\
\text { (R) }\end{array}$ & $(1,3,5)$ & TFN \\
\hline $\begin{array}{l}\text { Medium } \\
\text { (M) }\end{array}$ & $(3 / 2,5 / 2,7 / 2)$ & TFN & $\begin{array}{l}\text { Medium } \\
\text { Impact (MI) }\end{array}$ & $(2,3,4)$ & TFN & $\begin{array}{l}\text { Occasional } \\
\text { (O) }\end{array}$ & $(3,5,7)$ & TFN \\
\hline $\begin{array}{l}\text { High } \\
(\mathrm{H})\end{array}$ & $(5 / 2,7 / 2,9 / 2)$ & TFN & & & & $\begin{array}{l}\text { Probable } \\
\text { (P) }\end{array}$ & $(5,7,9)$ & TFN \\
\hline $\begin{array}{l}\text { Very High } \\
\text { (VH) }\end{array}$ & $(7 / 2,9 / 2,5,5)$ & TrFN & $\begin{array}{l}\text { High Impact } \\
\text { (HI) }\end{array}$ & $(3,4,5)$ & TFN & $\begin{array}{l}\text { Frequent } \\
\text { (F) }\end{array}$ & $(7,9,10,10)$ & TrFN \\
\hline
\end{tabular}




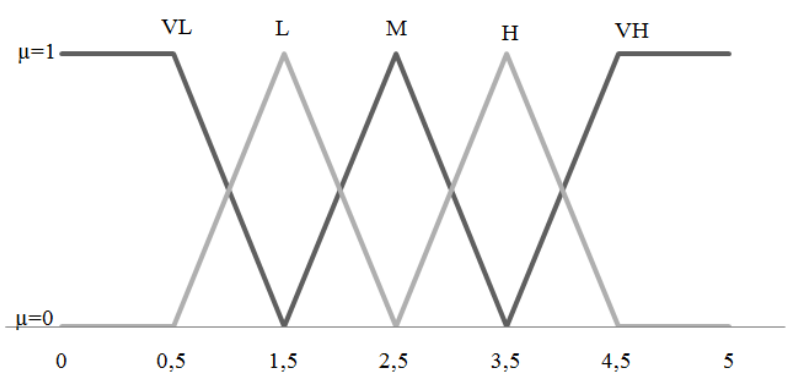

Figure 2. Linguistic variables for $\mathrm{C}_{1}$, time of operation

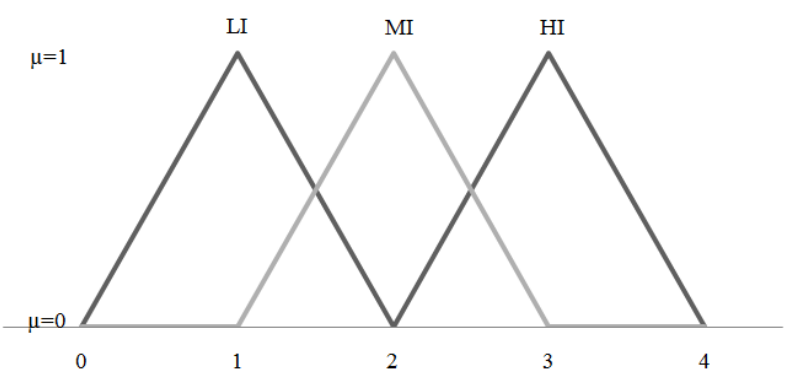

Figure 3. Linguistic variables for $\mathrm{C}_{2}$, modality of execution

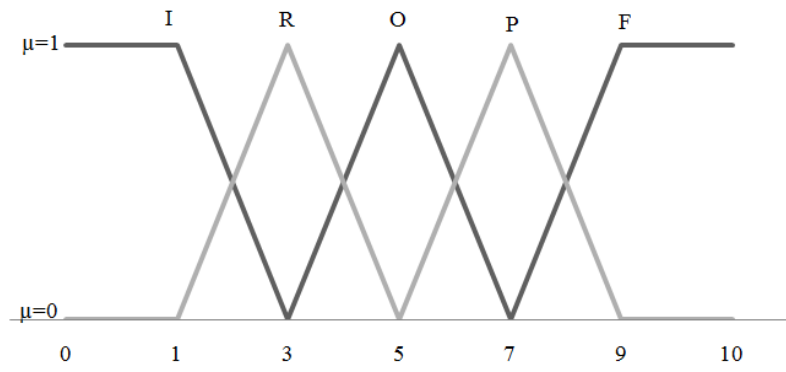

Figure 4. Linguistic variables for $\mathrm{C}_{3}$, frequency of occurrence

Ratings of failure modes against criteria are synthesized in Table IX along with the weighted normalized matrix obtained by the FTOPSIS method. The resulting closeness coefficients values of are reported in Table X. 
TABLE IX. WEIGHTED AND NORMALIZED MATRIX

\begin{tabular}{|c|c|c|c|c|c|c|c|c|c|c|c|c|c|c|c|}
\hline \multirow{2}{*}{$\frac{\text { ID }-\mathbf{F M}}{1 \mathrm{~A}}$} & \multirow{2}{*}{$\begin{array}{c}\mathbf{C}_{1} \\
\mathrm{VH}\end{array}$} & \multirow{2}{*}{$\begin{array}{l}\mathbf{C}_{2} \\
\mathrm{HI}\end{array}$} & \multirow{2}{*}{\begin{tabular}{c|}
$\mathrm{C}_{3}$ \\
$\mathrm{R}$
\end{tabular}} & \multicolumn{4}{|c|}{$\mathbf{C}_{1}$} & \multicolumn{4}{|c|}{$\mathrm{C}_{2}$} & \multicolumn{4}{|c|}{$\mathrm{C}_{3}$} \\
\hline & & & & 0.0409 & 0.0409 & 0.045444 & .058429 & 0.04925 & 0.065667 & 0.065667 & 0.0985 & 0.0788 & 0.131333 & 0.131333 & 0.394 \\
\hline $1 \mathrm{~B}$ & $\mathrm{VH}$ & $\mathrm{HI}$ & $\mathrm{O}$ & 0.0409 & 0.0409 & 0.045444 & 0.058429 & 0.04925 & 0.065667 & 0.065667 & 0.0985 & 0.056286 & 0.0788 & 0.0788 & 0.131333 \\
\hline $1 \mathrm{C}$ & $\mathrm{VH}$ & $\mathrm{HI}$ & $\mathrm{R}$ & 0.0409 & 0.0409 & 0.045444 & 0.058429 & 0.04925 & 0.065667 & 0.065667 & 0.0985 & 0.0788 & 0.131333 & 0.131333 & 0.394 \\
\hline $1 \mathrm{D}$ & $\mathrm{L}$ & MI & $\mathrm{O}$ & 0.0818 & 0.136333 & 0.136333 & 0.409 & 0.065667 & 0.0985 & 0.0985 & 0.197 & 0.056286 & 0.0788 & 0.0788 & 0.131333 \\
\hline $2 \mathrm{~A}$ & $\mathrm{H}$ & $\mathrm{HI}$ & $\mathrm{P}$ & 0.045444 & 0.058429 & 0.058429 & 0.0818 & 0.04925 & 0.065667 & 0.065667 & 0.0985 & 0.043778 & 0.056286 & 0.056286 & 0.0788 \\
\hline $2 \mathrm{~B}$ & $\mathrm{~L}$ & MI & $\mathrm{P}$ & 0.0818 & 0.136333 & 0.136333 & 0.409 & 0.065667 & 0.0985 & 0.0985 & 0.197 & 0.043778 & 0.056286 & 0.056286 & 0.0788 \\
\hline $2 \mathrm{C}$ & $\mathrm{L}$ & MI & $\mathrm{P}$ & 0.0818 & 0.136333 & 0.136333 & 0.409 & 0.065667 & 0.0985 & 0.0985 & 0.197 & & 0.056286 & 0.056286 & 0.0788 \\
\hline $3.1 \mathrm{~A}$ & VH & $\mathrm{HI}$ & $\mathrm{R}$ & 0.0409 & 0.0409 & 0.045444 & 0.058429 & 0.04925 & 0.065667 & 0.065667 & 0.0985 & 0.0788 & 0.131333 & 0.131333 & 0.394 \\
\hline $3.1 \mathrm{~B}$ & $\mathrm{VH}$ & HI & $\mathrm{R}$ & & & & & 0.04925 & & & & & & & \\
\hline $3.2 \mathrm{~A}$ & VH & $\mathrm{HI}$ & $\mathrm{R}$ & 0.0409 & 0.0409 & 0.045444 & 0.058429 & 0.04925 & 0.065667 & 0.065667 & 0.0985 & & 0.13 & 0.13 & \\
\hline $3.2 \mathrm{~B}$ & VH & $\mathrm{HI}$ & $\mathrm{R}$ & 0.0409 & 0.0409 & 0.045444 & 0.058429 & 0.04925 & 0.065667 & 0.065667 & 0.0985 & 0.0788 & 0.131333 & 0.131333 & 0.394 \\
\hline $3.3 \mathrm{~A}$ & $\mathrm{H}$ & MI & $\mathrm{O}$ & 0.045444 & 0.058429 & 0.058429 & 0.0818 & 0.065667 & 0.0985 & 0.0985 & 0.197 & 0.056286 & 0.0788 & 0.0788 & 0.131333 \\
\hline & $\mathrm{L}$ & MI & $\mathrm{P}$ & & & & & & & & & & & & \\
\hline & $\mathrm{M}$ & $\mathrm{HI}$ & $\mathrm{R}$ & 0.05 & & & & & & & & & & & \\
\hline $4.1 .2 \mathrm{~A}$ & VH & MI & $\mathrm{O}$ & & & & & & & & & & & & \\
\hline $4.1 .2 \mathrm{~B}$ & $\mathrm{VH}$ & MI & $\mathrm{R}$ & 0.0409 & 0.0409 & 0.045444 & 0.058429 & 0.065667 & 0.0985 & 0.0985 & 0.197 & 0.0788 & 0.131333 & 0.131333 & 0.394 \\
\hline $4.1 .3 \mathrm{~A}$ & $\mathrm{~L}$ & MI & $\mathrm{P}$ & 0.0818 & 0.136333 & 0.136333 & 0.409 & 0.065667 & 0.0985 & 0.0985 & 0.197 & 0.043778 & 0.056286 & 0.056286 & 0.0788 \\
\hline & $\mathrm{L}$ & MI & $\mathrm{P}$ & & & & & & & & & & & & \\
\hline & $\mathrm{H}$ & MI & $\mathrm{R}$ & & & & & & & & & & & & 0.394 \\
\hline & $\mathrm{H}$ & MI & $\mathrm{R}$ & & & & & & & & & & & & \\
\hline $4.2 .2 \mathrm{~A}$ & $\mathrm{H}$ & MI & $\mathrm{P}$ & 0.045444 & 0.058429 & 0.058429 & 0.0818 & 0.065667 & 0.0985 & & & 0.043778 & 0.056286 & 0.056286 & 0.0788 \\
\hline 4.2.2B & $\mathrm{L}$ & MI & $\mathrm{O}$ & 0.0818 & 0.136333 & 0.136333 & & 0.065667 & 0.0985 & & 0.197 & 0.056286 & 0.0788 & 0.0788 & 0.131333 \\
\hline $4.2 .2 \mathrm{C}$ & $\mathrm{M}$ & MI & $\mathrm{O}$ & 0.058429 & 0.0818 & 0.0818 & 0.136333 & 0.065667 & 0.0985 & 0.0985 & 0.197 & 0.056286 & 0.0788 & 0.0788 & 0.131333 \\
\hline & $\mathrm{H}$ & MI & $\mathrm{P}$ & 0.045444 & 0.058429 & 0.058429 & & 0.065667 & & & & & 0.056286 & 0.056286 & 0.0788 \\
\hline 4.2.3B & $\mathrm{L}$ & MI & $\mathrm{O}$ & 0.0818 & 0.136333 & 0.136333 & 0.409 & 0.065667 & & 0.0985 & 0.197 & 0.056286 & 0.0788 & 0.0788 & 0.131333 \\
\hline $4.2 .3 \mathrm{C}$ & M & MI & $\mathrm{O}$ & 0.058429 & 0.0818 & 0.0818 & .136333 & 0.065667 & 0.0985 & 0.0985 & 0.197 & 0.056286 & 0.0788 & 0.0788 & 0.131333 \\
\hline $5.1 \mathrm{~A}$ & $\mathrm{~L}$ & MI & $\mathrm{R}$ & 0.0818 & 0.136333 & 0.136333 & 0.409 & 0.065667 & 0.0985 & 0.0985 & 0.197 & 0.0788 & 0.131333 & 0.131333 & 0.394 \\
\hline
\end{tabular}




\begin{tabular}{|c|c|c|c|c|c|c|c|c|c|c|c|c|c|c|c|}
\hline $5.1 \mathrm{~B}$ & $\mathrm{M}$ & MI & $\mathrm{R}$ & 0.058429 & 0.0818 & 0.0818 & 0.136333 & 0.065667 & 0.0985 & 0.0985 & 0.197 & 0.0788 & 0.131333 & 0.131333 & 0.394 \\
\hline $5.2 .1 \mathrm{~A}$ & $\mathrm{~L}$ & MI & $\mathrm{R}$ & 0.0818 & 0.136333 & 0.136333 & 0.409 & 0.065667 & 0.0985 & 0.0985 & 0.197 & 0.0788 & 0.131333 & 0.131333 & 0.394 \\
\hline $5.2 .1 \mathrm{~B}$ & $\mathrm{M}$ & MI & $\mathrm{O}$ & 0.058429 & 0.0818 & 0.0818 & 0.136333 & 0.065667 & 0.0985 & .0985 & 197 & .056286 & 0.0788 & 0.0788 & .131333 \\
\hline $5.2 .1 \mathrm{C}$ & $\mathrm{L}$ & MI & $\mathrm{P}$ & 0.0818 & 136333 & 0.136333 & 0.409 & 67 & 85 & 985 & 197 & 778 & 286 & 286 & 788 \\
\hline $5.2 .1 \mathrm{D}$ & $\mathrm{H}$ & MI & $\mathrm{O}$ & 0.045444 & 0.058429 & 0.058429 & 0.0818 & 0.065667 & 0.0985 & 0985 & .197 & 056286 & 0.0788 & 0.0788 & 0.131333 \\
\hline $5.2 .1 \mathrm{E}$ & $\mathrm{M}$ & MI & $\mathrm{P}$ & 0.058429 & 0.0818 & 0.0818 & 0.136333 & 0.065667 & 0.0985 & 0.0985 & 0.197 & 0.043778 & 0.056286 & 0.056286 & 0.0788 \\
\hline $5.2 .2 \mathrm{~A}$ & $\mathrm{M}$ & MI & $\mathrm{R}$ & 29 & 0.0 & 0 & 33 & 7 & 5 & .0985 & .197 & $0 \Omega$ & $012>$ & 23 & 0 \\
\hline $5.2 .2 \mathrm{~B}$ & $\mathrm{~L}$ & MI & $\mathrm{R}$ & 0.0818 & 0.150553 & 0.136333 & .409 & 667 & 0.0985 & 0.0985 & 197 & 788 & 33 & 3 & 394 \\
\hline $5.2 .2 \mathrm{C}$ & $\mathrm{M}$ & $\mathrm{HI}$ & $\mathrm{P}$ & 0.058429 & 0.0818 & 0.0818 & 0.136333 & 0.04925 & .065667 & 0.065667 & 0.0985 & 0.043778 & 0.056286 & 0.056286 & 0.0788 \\
\hline $5.2 .2 \mathrm{D}$ & $\mathrm{H}$ & $\mathrm{HI}$ & $\mathrm{P}$ & 0.045444 & 0.058429 & 0.058429 & 0.0818 & 0.04925 & 0.065667 & 0.065667 & 0.0985 & 0.043778 & 0.056286 & 0.056286 & 0.0788 \\
\hline $5.3 .1 \mathrm{~A}$ & $\mathrm{H}$ & $\mathrm{HI}$ & $\mathrm{O}$ & 0.045444 & 0.058429 & 0.058429 & 0.0818 & 0 & 0.065667 & 0.065667 & 0.0985 & 0.056286 & 0.0788 & 0.0788 & 0.131333 \\
\hline 5.3.1B & $\mathrm{M}$ & $\mathrm{HI}$ & $\mathrm{P}$ & 0.058429 & 0.0818 & 0.0818 & 0.136333 & 0.04925 & 0.065667 & 0.065667 & 0.0985 & 0.043778 & 0.056286 & 0.056286 & 0.0788 \\
\hline $5.3 .1 \mathrm{C}$ & $\mathrm{M}$ & $\mathrm{HI}$ & $\mathrm{R}$ & 0.058429 & 0.0818 & 0.0818 & 0.136333 & 0.04925 & 0.065667 & 0.065667 & 0.0985 & 0.0788 & 0.131333 & 0.131333 & 0.394 \\
\hline $5.3 .2 \mathrm{~A}$ & $\mathrm{M}$ & HI & $\mathrm{R}$ & 0.058429 & 0.0818 & 0.0818 & 0.136333 & 0.04925 & 0.065667 & 0.065667 & 0.0985 & 0.0788 & 0.131333 & 0.131333 & 0.394 \\
\hline
\end{tabular}


TABLE $\mathrm{X}$. Distances and Closeness Coefficient Values

\begin{tabular}{|c|c|c|c|c|}
\hline ID - FM & Failure Mode (FM) & $d_{i}^{-}$ & $d_{i}^{*}$ & $C C_{i}$ \\
\hline $1 \mathrm{~A}$ & Broken PTO mechanism & 0.340325 & 2.70939 & 0.11159 \\
\hline $1 \mathrm{~B}$ & Worn PTO bearings & 0.209601 & 2.798121 & 0.06969 \\
\hline $1 \mathrm{C}$ & Broken PTO universal joint shafts & 0.340325 & 2.70939 & 0.11159 \\
\hline $1 \mathrm{D}$ & General electrical system fault & 0.445381 & 2.619742 & 0.14531 \\
\hline $2 \mathrm{~A}$ & Overheated oil & 0.194575 & 2.810765 & 0.06474 \\
\hline $2 \mathrm{~B}$ & Insufficient oil level & 0.414908 & 2.646928 & 0.13551 \\
\hline $2 \mathrm{C}$ & Clogged filters & 0.414908 & 2.646928 & 0.13551 \\
\hline $3.1 \mathrm{~A}$ & Fault in distribution system (start-up pump) & 0.340325 & 2.70939 & 0.11159 \\
\hline $3.1 \mathrm{~B}$ & Mechanical fault (start-up pump) & 0.340325 & 2.70939 & 0.11159 \\
\hline $3.2 \mathrm{~A}$ & Stopped start-up engine & 0.340325 & 2.70939 & 0.11159 \\
\hline $3.2 \mathrm{~B}$ & Mechanical fault (start-up engine) & 0.340325 & 2.70939 & 0.11159 \\
\hline $3.3 \mathrm{~A}$ & Fault in electrical system & 0.278047 & 2.73963 & 0.09214 \\
\hline 4.1.1A & Empty water tank & 0.414908 & 2.646928 & 0.13551 \\
\hline 4.1.1B & Hole in water tank & 0.387407 & 2.666641 & 0.12685 \\
\hline $4.1 .2 \mathrm{~A}$ & Fault in distribution system of the water pump & 0.262598 & 2.754173 & 0.08705 \\
\hline 4.1.2B & Mechanical fault of the water pump & 0.393322 & 2.665441 & 0.12859 \\
\hline $4.1 .3 \mathrm{~A}$ & No working nozzles & 0.414908 & 2.646928 & 0.13551 \\
\hline 4.1.3B & Clogged nozzles & 0.414908 & 2.646928 & 0.13551 \\
\hline $4.2 .1 \mathrm{~A}$ & Fault distribution system in Pump I & 0.408771 & 2.650899 & 0.13360 \\
\hline 4.2.1B & Mechanical fault in Pump I & 0.408771 & 2.650899 & 0.13360 \\
\hline $4.2 .2 \mathrm{~A}$ & Damaged brush or roller & 0.247573 & 2.766816 & 0.08213 \\
\hline 4.2.2B & Faulty hydraulic cylinders & 0.445381 & 2.619742 & 0.14531 \\
\hline $4.2 .2 \mathrm{C}$ & Fault in electrical system & 0.30968 & 2.711423 & 0.10251 \\
\hline $4.2 .3 \mathrm{~A}$ & Damaged brush or roller & 0.247573 & 2.766816 & 0.08213 \\
\hline $4.2 .3 \mathrm{~B}$ & Faulty hydraulic cylinders & 0.445381 & 2.619742 & 0.14531 \\
\hline $4.2 .3 \mathrm{C}$ & Fault in electrical system & 0.30968 & 2.711423 & 0.10251 \\
\hline $5.1 \mathrm{~A}$ & Fault in distribution system (loading-pump) & 0.576105 & 2.531011 & 0.18541 \\
\hline $5.1 \mathrm{~B}$ & Mechanical fault (loading-up pump) & 0.440405 & 2.622692 & 0.14378 \\
\hline $5.2 .1 \mathrm{~A}$ & Fault in hydraulic engine (rear roller) & 0.576105 & 2.531011 & 0.18541 \\
\hline $5.2 .1 \mathrm{~B}$ & Fault in actuator (rear roller) & 0.30968 & 2.711423 & 0.10251 \\
\hline 5.2.1C & Worn bristles (rear roller) & 0.414908 & 2.646928 & 0.13551 \\
\hline 5.2.1D & Fault in support arm (rear roller) & 0.278047 & 2.73963 & 0.09214 \\
\hline $5.2 .1 \mathrm{E}$ & Slackened pivots or worn journal boxes (rear roller) & 0.279207 & 2.738609 & 0.09252 \\
\hline $5.2 .2 \mathrm{~A}$ & Fault in Pump III (elevator plant) & 0.440405 & 2.622692 & 0.14378 \\
\hline 5.2.2B & Fault in hydraulic engine (elevator plant) & 0.576105 & 2.531011 & 0.18541 \\
\hline $5.2 .2 \mathrm{C}$ & Broken skid (elevator plant) & 0.226209 & 2.782558 & 0.07518 \\
\hline 5.2.2D & Broken chain (elevator plant) & 0.194575 & 2.810765 & 0.06474 \\
\hline 5.3.1A & Fault in support arm in the tank structure (emptying system) & 0.225049 & 2.783579 & 0.07480 \\
\hline 5.3.1B & $\begin{array}{l}\text { Slackened pivots or worn journal boxes in the tank structure } \\
\text { (emptying system) }\end{array}$ & 0.226209 & 2.782558 & 0.07518 \\
\hline 5.3.1C & $\begin{array}{c}\text { Overturning cylinder fault in the tank structure (emptying } \\
\text { system) }\end{array}$ & 0.387407 & 2.666641 & 0.12685 \\
\hline $5.3 .2 \mathrm{~A}$ & Broken or stopped releasing cylinder of the elevator plant & 0.387407 & 2.666641 & 0.12685 \\
\hline
\end{tabular}


Table XI reports the ranking of failure modes deemed to be the most critical as characterized by $C C_{i}$ values smaller than or equal to $10 \%$, namely very close to the negative solution.

\section{TABLE XI. RANKING OF FAILURE MODES}

\begin{tabular}{|c|c|}
\hline Ranking & ID - FM \\
\hline $1^{\text {st }}$ & $2 \mathrm{~A}$ \\
$2^{\text {nd }}$ & $5.2 .2 \mathrm{D}$ \\
$3^{\text {rd }}$ & $1 \mathrm{~B}$ \\
$4^{\text {th }}$ & $5.3 .1 \mathrm{~A}$ \\
$5^{\text {th }}$ & $5.2 .2 \mathrm{C}$ \\
$6^{\text {th }}$ & $5.3 .1 \mathrm{~B}$ \\
$7^{\text {th }}$ & $4.2 .2 \mathrm{~A}$ \\
$8^{\text {th }}$ & $4.2 .3 \mathrm{~A}$ \\
$9^{\text {th }}$ & $4.1 .2 \mathrm{~A}$ \\
$10^{\text {th }}$ & $3.3 \mathrm{~A}$ \\
$11^{\text {th }}$ & $5.2 .1 \mathrm{D}$ \\
$12^{\text {th }}$ & $5.2 .1 \mathrm{E}$ \\
\hline
\end{tabular}

To test the influence of criteria weights on the ranking results, a sensitivity analysis is finally carried out by varying the vector of criteria weights obtainable by means of the group decision process described in Section 3.1. For each vector of weights, failure modes deemed to be the most critical are those characterized by a $C C_{i}$ value smaller than or equal to $10 \%$ (Table XII).

TABLE XII. SENSITIVITY ANALYSIS RESULTS

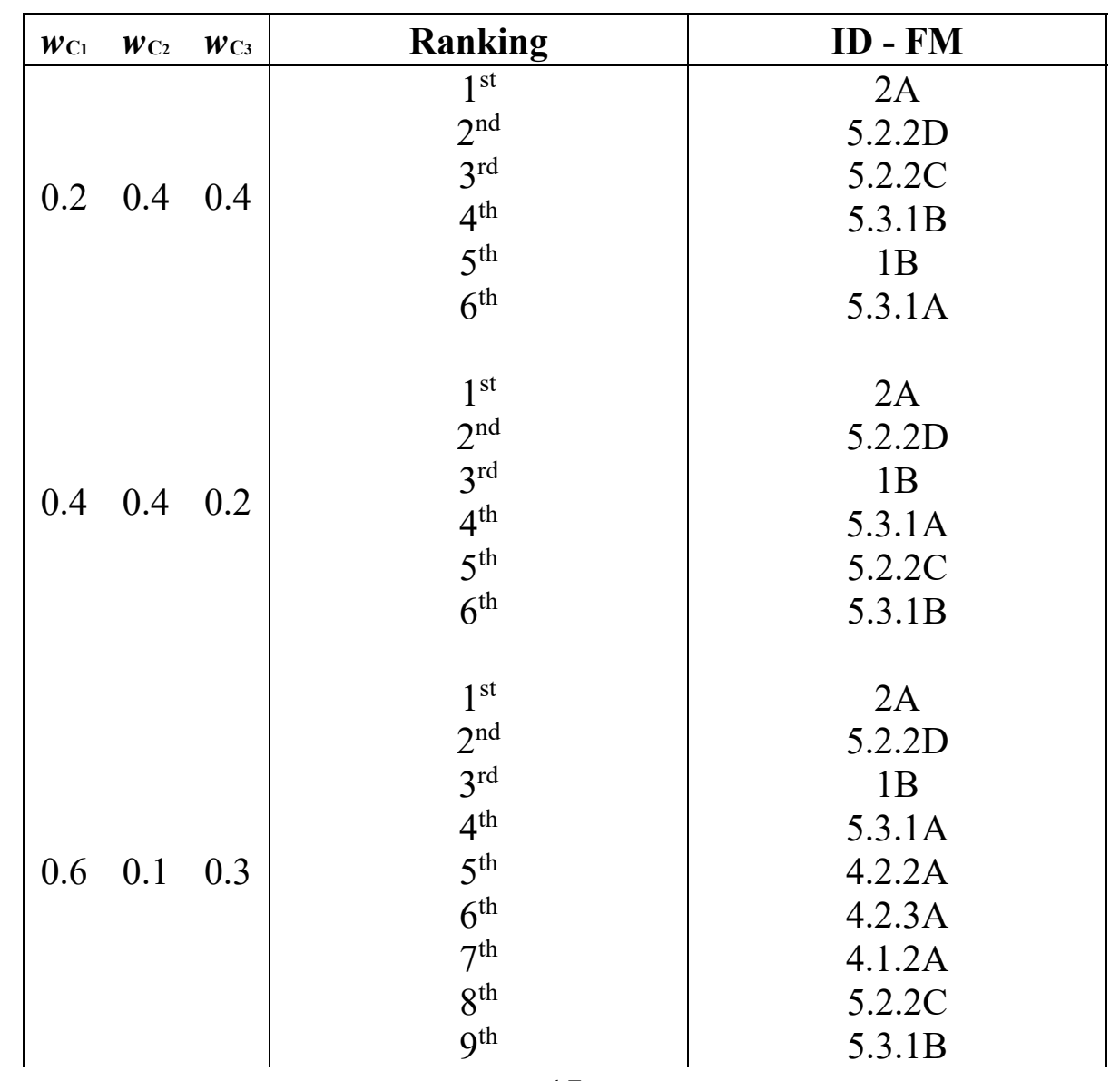




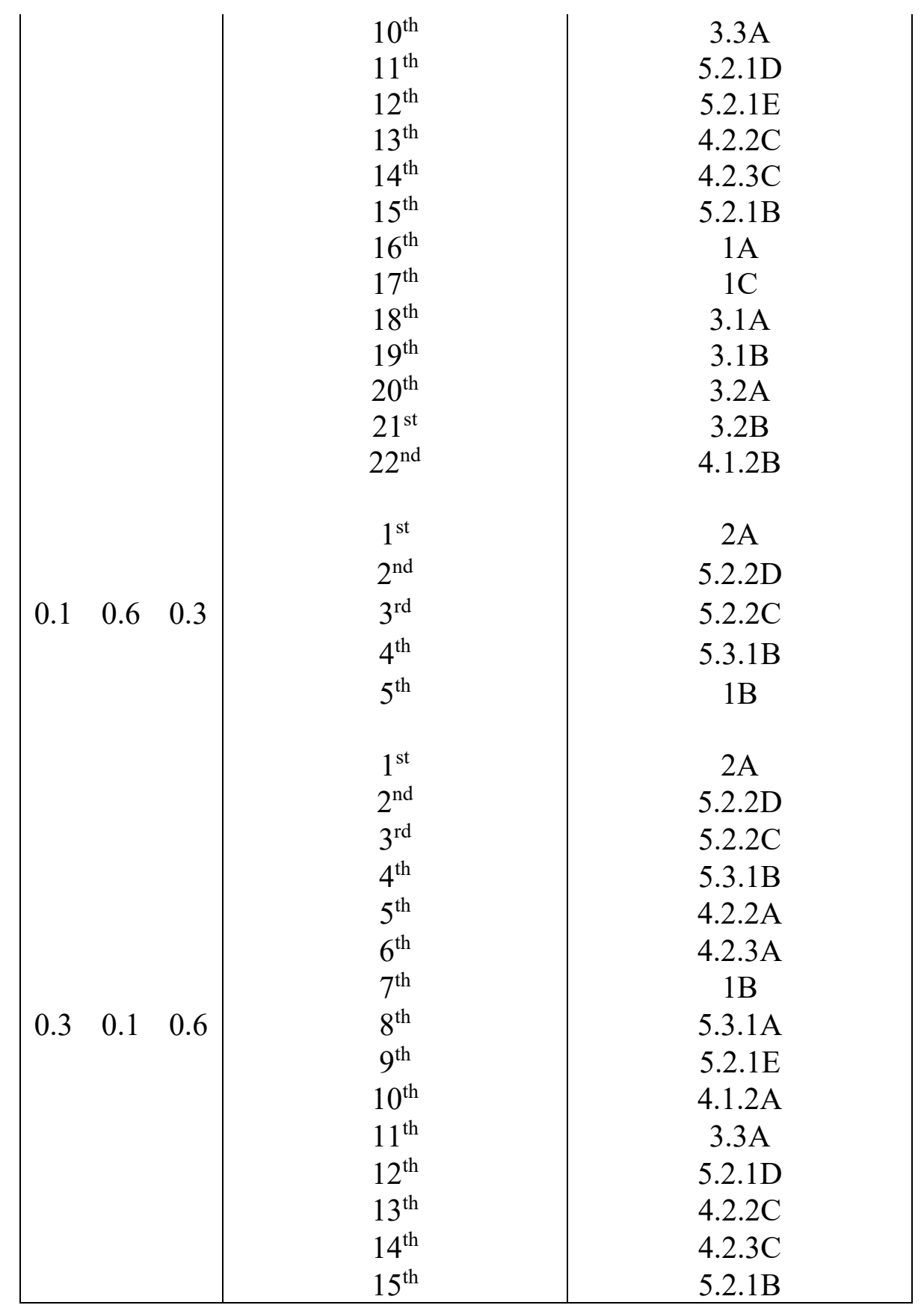

Table XII shows that the two first positions are always taken by failure modes 2A and 5.2.2 D for all the considered scenarios that also coincide with results of Table XI.

Table XII shows high-level critical failure modes 5.2.2.D (overheated oil) and 2.A (broken chain). Thus, as such a type of analysis suggests, for adequate scheduling and appropriate maintenance actions (both preventive and corrective) it is fundamental to avoid system faults and inadequate operational conditions. The diagram block in Figure 1 shows how the failure mode 2.A implies a fault for the entire system. 


\section{Conclusions}

The proposed combined approach considers the bond established between reliability analyses and multi-criteria decision methods as strategic in the maintenance management of complex systems. The approach starts from the need to make an in-depth analysis of the reliability features of the system under study and identify all possible failure modes by means of the FMECA. Ranking of all failure modes is then obtained through FTOPSIS which enables a prioritization of alternatives on the basis of various evaluation criteria. FTOPSIS is also effective in managing data uncertainty because it uses fuzzy numbers. The mentioned evaluation criteria have been weighted by applying the AHP method to aggregate judgments given by a group of experts.

When applied to the real-world application case of a street cleaning vehicle, FMECA was approached by considering different evaluation criteria with respect to the classical RPN index calculation. All possible analyzed failure modes were classified by applying FTOPSIS and a maintenance team of experts was involved in weighting evaluation criteria through AHP. Therefore, the obtained closeness coefficients were used as a driver during the planning of maintenance activities in terms of priorities because they highlight the main critical failure modes. A sensitivity analysis is finally performed to test the influence of criteria weights on the ranking results.

\section{Acknowledgements}

The authors give a special acknowledgment to John Rawlins, a qualified member of the Institute of Translation and Interpreting of UK, for his support in revising the use of English in this paper. 


\section{References}

[1] ISO 55000. Asset management overview, principles and terminology. International Standard Organization, Switzerland 2014.

[2] Liu X, Wang W, Peng R. An integrated production, inventory and preventive maintenance model for a multi-product production system. Reliability Engineering and System Safety 2015;137:76-86.

[3] Bertolini M, Bevilacqua M, Massini R. FMECA approach to product traceability in the food industry. Food control 2006;17(2):137-145.

[4] Antonovsky A, Pollock C, Straker L. System reliability as perceived by maintenance personnel on petroleum production facilities. Reliability Engineering and System Safety 2016;152:58-65.

[5] Jun L, Huibin X. Reliability Analysis of Aircraft Equipment Based on FMECA Method. Physics Procedia 2012;25:1816-1822.

[6] Bosse S, Splieth M, Turowski K. Multi-objective optimization of IT service availability and costs. Reliability Engineering and System Safety 2016;147:142-155.

[7] Sidibé IB, Khatab A, Diallo C, Adjallah KH. Kernel estimator of maintenance optimization model for a stochastically degrading system under different operating environments. Reliability Engineering and System Safety 2016;147:109-116.

[8] Panteleev VV, Kamaev VA, Kizim AV. Developing a Model of Equipment Maintenance and Repair Process at Service Repair Company Using Agent-Based Approach. Procedia Technology 2014;16:1072-1079.

[9] Certa A, Enea M, Lupo T. ELECTRE III to dynamically support the decision maker about the periodic replacements configurations for a multi-component system. Decision Support Systems 2013;55:126-134.

[10]Certa A, Enea M, Galante G, Lupo T. A Multi-Objective Approach to Optimize a Periodic Maintenance Policy, International Journal of Reliability. Quality and Safety Engineering 2012;19(6):1240002.

[11]Taghipour S, Banjevic D. Periodic inspection optimization models for a reparable system subjected to hidden failure. IEEE Transactions on Reliability 2011;60(1):275-285.

[12] Yang L, Ma X, Zhai Q, Zhao Y. A delay time model for a mission-based system subject to periodic and random inspection and postponed replacement. Reliability Engineering \& System Safety 2016;150:96-104.

[13]EN 60812 Standard, Analysis techniques for system reliability - Procedure for failure mode and effects analysis (FMEA) 2006. 
[14]Koning J, Jaspers R, Doornink J, Ouwehand B, Klinkhamer F, Snijders B, Sadakov S, Heemskerk C. Maintenance implications of critical components in ITER CXRS upper port plug design. Fusion Engineering and Design 2009;84(7-11):1091-1094.

[15]Aven T. Supplementing quantitative risk assessments with a stage addressing the risk understanding of the decision maker. Reliability Engineering and System Safety 2016;152:5157.

[16] Vernez D, Vuille F. Method to assess and optimise dependability of complex macro-systems: Application to a railway signalling system. Safety Science 2009;47(3):382-394.

[17]Carmignani G. An integrated structural framework to cost-based FMECA: The priority-cost FMECA. Reliability Engineering \& System Safety 2009;94(4):861-871.

[18]Bevilacqua M, Braglia M, Gabbrielli R. Monte Carlo simulation approach for a modified FMECA in a power plant. Quality and Reliability Engineering International 2000;16(14):313324.

[19] Yang J, Huang HZ, He LP, Zhu SP, Wen D. Risk evaluation in failure mode and effects analysis of aircraft turbine rotor blades using Dempster-Shafer evidence theory under uncertainty. Engineering Failure Analysis 2011;18(8):2084-2092.

[20] Shafer G. A Mathematical Theory of Evidence. New Jersey: Princeton University; 1976.

[21]Curcurù G, Galante GM, La Fata CM. A Dempster-Shafer Theory-Based Approach to Compute the Birnbaum Importance Measure under Epistemic Uncertainty. International Journal of Applied Engineering Research 2016;11(21):10574-10585, ISSN 0973-4562.

[22] Curcurù G, Galante GM, La Fata CM. An imprecise Fault Tree Analysis for the estimation of the Rate of OCcurrence Of Failure (ROCOF). Journal of Loss Prevention in the Process Industries 2013;6:1285-1292.

[23] Liu HC, Liu L, Liu N. Risk evaluation approaches in failure mode and effects analysis: A literature review. Expert Systems with Applications 2013;40:828-838.

[24]Braglia M. MAFMA: multi-attribute failure mode analysis. International Journal of Quality and Reliability Management 2000;17:1017-1033.

[25] Saaty TL. The Analytic Hierarchy Process. New York: McGraw Hill Company, 1994.

[26] Braglia M, Bevilacqua M. Fuzzy modeling and analytical hierarchy processing as a means of quantifying risk levels associated with failure modes in production systems. Technology, Law and Insurance 2000;5:125-134.

[27]Zammori F, Gabbrielli R. ANP/RPN: A multi criteria evaluation of the risk priority number. Quality and Reliability Engineering International 2011;28:85-104.

[28] Saaty TL, Ozdemir MS. The encyclicon: a dictionary of decisions with dependence and feedback based on Analytic Network Process. Pittsburgh: RWS Publications; 2005. 
[29]Emovon I, Norman RA, Murphy AJ, Pazouki K. An integrated multicriteria decision making methodology using compromise solution methods for prioritizing risk of marine machinery systems. Ocean Engineering 2015;105:92-103.

[30]Liu HC, Mao LX, Zhang ZY, Li P. Induced aggregation operators in the VIKOR method and its application in material selection. Applied Mathematical Modelling 2013;37(9):6325-6338.

[31]Braglia M, Frosolini M, Montanari R. Fuzzy TOPSIS Approach for Failure Mode, Effects and Criticality Analysis. Quality and Reliability Engineering International 2003;19:425-443.

[32] Chen CT. Extensions of the TOPSIS for group decision-making under fuzzy environment. Fuzzy Sets and Systems 2000;114(1):1-9.

[33]Hwang CL, Yoon K. Multiple attribute decision making: Methods and Applications. New York: Springer-Verlag; 1981.

[34] Aiello G, Enea M, Galante G, La Scalia G. Clean Agent Selection Approached by Fuzzy TOPSIS Decision-Making Method. Fire Technology 2009;45:405-418.

[35]Rostamzadeh R, Sofian S. Prioritizing effective $7 \mathrm{Ms}$ to improve production systems performance using fuzzy AHP and fuzzy TOPSIS (case study). Expert Systems with Applications 2011;38(5):5166-5177.

[36] Chan FTS, Kumar N, Tiwari MK, Lau HCW, Choy KL. Global supplier selection: a fuzzyAHP approach. International Journal of Production Research 2008;46(14):3825-3857.

[37]Kutlu AC, Ekmekçioğlu M. Fuzzy failure modes and effects analysis by using fuzzy TOPSISbased fuzzy AHP. Expert Systems with Applications 2012;39(1):61-67.

[38]Roy B. Classement et choix en presence de points de vue multiples (la method ELECTRE). Revue Informatique et Recherche Operationnelle 1968;8:57-75.

[39] Certa A, Enea M, Galante GM, La Fata CM. ELECTRE TRI-based approach to the failure modes classification on the basis of risk parameters: An alternative to the risk priority number, Computers \& Industrial Engineering 2017;108:100-110.

[40]Certa A, Hopps F, Inghilleri R, La Fata CM. A Dempster Shafer Theory-based approach to the Failure Mode, Effects and Criticality Analysis (FMECA) under epistemic uncertainty: application to the propulsion system of a fishing vessel. Reliability Engineering \& System Safety 2017;159:69-79.

[41]Carpitella S, Certa A, Galante G, Izquierdo J, La Fata CM. The FTOPSIS method to support FMECA analyses. Proceeding of 22th ISSAT International Conference on Reliability and Quality in Design (2016) Los Angeles, California, USA, August 4-6.

[42] Berrittella M, Certa A, Enea M, Zito P. Transport policy and climate change: how to decide when experts disagree. Environmental Science \& Policy 2008;11(4):307-314. 
[43] Srdjevic B. Linking analytic hierarchy process and social choice methods to support group decision-making in water management. Decision Support Systems 2007;42:2261-2273.

[44]Lai VS, Wong BK, Cheung W. Group decision making in a multiple criteria environment: A case using AHP in software selection. European Journal of Operational Research 2002;137:134-144.

[45]Delgado-Galván X, Izquierdo J, Benítez J, Pérez-García R. Joint Stakeholder Decision-Making on the Management of the Silao-Romita Aquifer Using AHP. Environmental Modelling \& Software 2014;51:310-322.

[46] Srdjevic B, Srdjevic Z, Blagojevic B, Suvocarev K. A two-phase algorithm for consensus building in AHP-group decision making. Applied Mathematical Modelling 2013;37(1011):6670-6682.

[47] Saaty TL. Fundamentals of decision making and priority theory with the analytic hierarchy process. Pittsburg: RWS Publication; 2000.

[48] Saaty TL. A scaling method for priorities in hierarchical structures. Journal of Mathematical Psychology 1977;15:234-281.

[49]Blagojevic B, Srdjevic B, Srdjevic Z, Zoranovic T. Heuristic aggregation of individual judgments in AHP group decision making using simulated annealing algorithm. Information Sciences 2016;330:260-273.

[50]Certa A, Enea M, Hopps F. A multi-criteria approach for the group assessment of an academic course: A case study. Studies in Educational Evaluation 2015;44:16-22.

[51] Saaty TL, The Analytic Hierarchy Process: Planning, Priority Setting and Resource Allocation. New York: McGraw-Hill; 1980.

[52]Benítez J, Delgado-Galván X, Izquierdo J, Pérez-García R. Achieving Matrix Consistency in AHP through Linearization. Applied Mathematical Modelling 2011;35:4449-4457.

[53]Benítez J, Delgado-Galván X, Izquierdo J, Pérez-García R. Improving consistency in AHP decision-making processes. Applied Mathematics and Computation 2012;219:2432-2441.

[54]Benítez J, Izquierdo J, Pérez-García R, Ramos-Martínez E. A simple formula to find the closest consistent matrix to a reciprocal matrix. Applied Mathematical Modelling 2014;38:3968-3974.

[55]Benítez J, Delgado-Galván X, Gutiérrez-Pérez JA, Izquierdo J. Balancing Consistency and Expert Judgment in AHP. Mathematical and Computer Modelling 2011;54:1785-1790.

[56]Benítez J, Delgado-Galván X, Izquierdo J, Pérez-García R. Consistent completion of incomplete judgments in decision making using AHP. Journal of Computational and Applied Mathematics 2015;290:412-422.

[57] Hu J, Du Y, Mo H, Wei D, Deng Y. A modified weighted TOPSIS to identify influential nodes in complex networks. Physica A: Statistical Mechanics and its Applications 2016;444:73-85. 
[58]Certa A, Enea M, Galante G, Lupo T. A multi-decision makers approach to select the maintenance plan for a multi-component system. Proceeding of 19th ISSAT International Conference on Reliability and Quality in Design (2013), Honolulu, Hawai, USA, August 5-7.

[59] Wang X, Yang F, Wei H, Zhang L. A new ranking method based on TOPSIS and possibility theory for multi-attribute decision making problem. Optik - International Journal for Light and Electron Optics 2015;126(24):4852-4860.

[60]Lourenzutti R, Krohling RA. A generalized TOPSIS method for group decision making with heterogeneous information in a dynamic environment. Information Science 2016;330:1-18.

[61] Shih HS. Incremental analysis for MCDM with an application to group TOPSIS. European Journal of Operational Research 2008;186:720-734.

[62] Chen CT, Lin CT, Huang SF. A fuzzy approach for supplier evaluation and selection in supply chain management. International Journal of production economics 2006;102(2):289-301.

[63] Kahlili-Damghani K, Sadi-Nezhad S. A hybrid fuzzy multiple criteria group decision making approach for sustainable project selection. Applied Soft Computing 2013;13(1):339-352. 